\title{
A new algorithm for the identification of dives reveals the foraging ecology of a shallow-diving seabird using accelerometer data
}

\author{
M. Cianchetti-Benedetti ${ }^{1}\left(\mathbb{D} \cdot\right.$ C. Catoni $^{2} \cdot$ A. Kato $^{3} \cdot$ B. Massa $^{4} \cdot$ P. Quillfeldt $^{1}$
}

Received: 16 November 2016 / Accepted: 10 February 2017

(C) Springer-Verlag Berlin Heidelberg 2017

\begin{abstract}
The identification of feeding events is crucial to our understanding of the foraging ecology of seabirds. Technology has made small devices, such as time-depth recorders (TDRs) and accelerometers available. However, TDRs might not be sensitive enough to identify shallow dives, whereas accelerometers might reveal more subtle behaviours at a smaller temporal scale. Due to the limitations of TDRs, the foraging ecology of many shallow-diving seabirds has been poorly investigated to date. We thus developed an algorithm to identify dive events in a shallowdiving seabird species, the Scopoli's shearwater, using only accelerometer data. The accuracy in the identification of dives using either accelerometers or TDRs was compared. Furthermore, we tested if the foraging behaviour of shearwaters changed during different phases of reproduction and with foraging trip type. Data were collected in Linosa
\end{abstract}

Responsible Editor: V. H. Paiva.

Reviewed by Undisclosed experts.

Electronic supplementary material The online version of this article (doi:10.1007/s00227-017-3106-0) contains supplementary material, which is available to authorized users.

M. Cianchetti-Benedetti

marco.cianchetti@gmail.com

1 Department of Animal Ecology and Systematics, Justus Liebig University Giessen, Heinrich-Buff-Ring 38, 35392 Giessen, Germany

2 Ornis italica, Piazza Crati, 15, 00199 Rome, Italy

3 Centre d'Etudes Biologiques de Chizé, UMR 7372 du CNRS-Université de La Rochelle, 79360 Villiers-en-Bois, France

4 Department of Agriculture and Forest Science, University of Palermo, V.le Scienze, 13, 90128 Palermo, Italy
Island $\left(35^{\circ} 51^{\prime} 33^{\prime \prime} \mathrm{N} ; 12^{\circ} 51^{\prime} 34^{\prime \prime} \mathrm{E}\right)$ from 12 June to 8 September 2015 by deploying accelerometer data loggers on 60 Scopoli's shearwaters. Four birds were also equipped with TDRs. TDRs recorded only $17.7 \%$ of the dives detected by the accelerometers using the algorithm. A total of $82.3 \%$ of dives identified by algorithm were too short or shallow to be detected by TDRs. Therefore, TDRs were not accurate enough to detect most of the dives in Scopoli's shearwaters, which foraged mostly close to the sea surface. Our data showed that birds performed shorter foraging trips and dived more frequently in the early chick-rearing period compared with the late chick-rearing and incubation phases. Furthermore, parents dived more frequently during short foraging trips. Our results suggest that Scopoli's shearwaters maximised their foraging effort (e.g. number of dives, short trips) during shorter foraging trips and during early chick-rearing.

\section{Introduction}

Accurate dive identification is necessary to understand the foraging ecology of a seabird species. Specifically, dive rates reflect the effort performed by birds to obtain food and are thus a measure of their foraging effort (Paiva et al. 2010a). Bio-logging devices, such as GPS and geolocators (Grémillet et al. 2004; Guilford et al. 2008; Dias et al. 2012), were extensively used to study the foraging behaviour of several seabirds. However, methods based on GPS or geolocators have intrinsic limitations to identify dives, because they rely on indirect measures of birds' foraging activity (Jonsen et al. 2005; Pinaud and Weimerskirch 2005; Tremblay et al. 2007). Conversely, time-depth recorders (TDRs) allow identifying dive occurrences by measurement of pressure. For this reason, this device was 
used in several seabirds (Shaffer et al. 2009; Ronconi et al. 2010; Paiva et al. 2010a; Grémillet et al. 2014). However, even high-accuracy TDRs might not be enough to identify feeding events occurring in shallow water or close to the sea surface. Indeed, during surface dives, a pressure sensor placed on an animal's back does not come in contact with water, or at least not enough to detect a dive. Given that most dives performed by shallow divers occur in the first meters of the water column (Grémillet et al. 2014; Rollingson et al. 2014), it is possible that shallow dives might have been underestimated due to the limitation of TDR.

Accelerometers can be used to identify and quantify animal movements (Shepard et al. 2008; Gómez Laich et al. 2011; Chimienti et al. 2016), and thus, they may help to determine shallow feeding events. Accelerometers were previously used to analyse details of diving behaviour in deep-diving birds (Ropert-Coudert et al. 2006; Sakamoto et al. 2009; Gómez Laich et al. 2011; Berlincourt et al. 2015). However, they have not been used in shallow-diving seabirds.

In the present study, we developed an algorithm to identify dives using accelerometer data in a shallow-diving species, the Scopoli's shearwater (Calonectris diomedea). Then, we compared the accuracy of dive identification by the algorithm with dives identified with TDR. This algorithm can increase our knowledge of Scopoli's shearwater feeding ecology as well as for other shallow-diving birds, whose dives cannot be reliably detected by TDRs.

Scopoli's shearwater is a pelagic seabird species nesting only in the Mediterranean basin and it is now considered as a separate species from Cory's shearwater (Calonectris borealis) (Sangster et al. 2012). As a typical Procellariiform seabird, Scopoli's shearwaters have single-chick broods and slow nestling development: the egg is laid during the second half of May to hatch in mid July. Both adults incubate the single egg alternately, and chick-feeding is shared between parents. During the chick-feeding period, adults forage at sea and return to feed the chick at night in the nesting burrow. Fledglings leave their nests from mid to end of October. Scopoli's shearwaters exploit a wide range of prey (Grémillet et al. 2014) and forage close to the sea surface (Zotier et al. 1999). During incubation, parents perform mainly long trips lasting several days (Cecere et al. 2013). During chick-rearing, on the other hand, adults perform short trips for chick-feeding and longer trips for selfprovisioning (Congdon et al. 2005; Magalhães et al. 2008). This dual-foraging strategy occurs especially in colonies surrounded by low productive waters (Granadeiro et al. 1998; Paiva et al. 2010a). Thus, under these conditions, short trips for chick-feeding occur in sub-optimal foraging areas close to the colony (Paiva et al. 2010b; Cecere et al. 2014) at the expense of the parental body condition (Weimerskirch et al. 1994). Conversely, long trips allow birds to visit more profitable areas far away from the colony to feed for themselves and replenish their energy reserves (Baduini and Hyrenbach 2003; Magalhães et al. 2008). The Scopoli's shearwaters nesting in Linosa Island are surrounded by low productive waters which are exploited by birds during short foraging trips (Cecere et al. 2014). Thus, we expected an increase of foraging effort performed by birds (i.e., high dive rates) during short trips compared with long trips.

We assessed how parental foraging effort changed over three different reproduction phases: incubation, early and late chick-rearing. Some differences in the foraging strategy between incubation and chick-rearing have been described in shearwaters (Shaffer et al. 2003; Navarro et al. 2007). However, differences in birds' foraging activity within the chick-rearing period have been poorly investigated. During chick-rearing, factors, such as body condition and chick nutritional state, can affect the length of foraging trips undertaken by the parents (Weimerskirch 1998; Quillfeldt et al. 2004; Ochi et al. 2010). Parents attend the chick almost every night during early chick-rearing, performing short foraging trips (in duration and distance from the colony), and they decrease their nest attendance over the chick-rearing period (Ramos et al. 2003). Therefore, we expect the highest foraging effort in early chickrearing. Finally, we investigated the effects of sex and time of the day on the foraging behaviour of Scopoli's shearwaters. Shearwater foraging activity occurs mostly during daytime (Shaffer et al. 2009). Indeed, diurnal foraging might be more profitable than nocturnal for visual predators (McNeil et al. 1993). However, Scopoli's shearwater also forages at night (Rubolini et al. 2015). At this time, shearwaters can take advantage on the migration to the surface of some prey species at night, such as crustaceans and squids (Spear et al. 2007). However, it still not clear how the night foraging activity in this species is related to the phase or reproduction. We expect that shearwaters increase their nocturnal foraging activity during the most energetic demanding phase (e.g., early chick-rearing). According to previous studies, we do not expect differences in foraging behaviour between sexes (Navarro et al. 2009, Ramos et al. 2009; Cecere et al. 2013).

\section{Methods}

\section{Data collection}

The study was carried out on Linosa, a small island $\left(5.43 \mathrm{~km}^{2}\right)$ located in the Sicilian Channel $\left(35^{\circ} 51^{\prime} 33^{\prime \prime} \mathrm{N}\right.$; $\left.12^{\circ} 51^{\prime} 34^{\prime \prime} \mathrm{E}\right)$, from 12 June to 8 September 2015. Linosa hosts the largest colony of Scopoli's shearwater with 10,000 breeding pairs (see Massa and Lo Valvo 1986). 
Most of the nests are located in natural caves and crevices in a volcanic substrate in the northern part of the island, in an area named "Mannarazza". We collected data on 60 complete foraging trips of different birds (29 females and 31 males) for a total of 232 days (Table 1). Four of the 60 birds, two during incubation and two during the chick-rearing period, were equipped with Axy-depth dataloggers (Technosmart Europe S.r.l) that weighed $6.5 \mathrm{~g}$ $(12 \times 31 \times 11 \mathrm{~mm})$. The Axy-depth logger consists of a triaxial accelerometer logger set at $25 \mathrm{~Hz}$ and a TDR (timedepth recorder) which recorded temperature and pressure at $1 \mathrm{~Hz}$ frequency with an accuracy of $0.1^{\circ} \mathrm{C}$ and $5 \mathrm{mBar}$ $(\approx 0.05 \mathrm{~m})$, respectively. The other 56 birds were equipped with Axy-3 accelerometer dataloggers (Technosmart Europe S.r.l) that weighed $3.5 \mathrm{~g}(9.5 \times 15 \times 4 \mathrm{~mm})$, recording tri-axial acceleration between -4 and $4 \mathrm{~g}$ at $25 \mathrm{~Hz}$ and temperature with an accuracy of $0.1^{\circ} \mathrm{C}$ at $1 \mathrm{~Hz}$. Axy-depth and Axy-3 have the same accelerometer components. During incubation, we monitored parental nest attendance by recording the identity of the bird using the ring number. Then, each bird was painted using non-toxic colour to identify it from the partner and avoid handling it again. During incubation, birds were captured at the nest and equipped with a device during the day, to avoid interfering with nocturnal turn-over of parents. After hatching, the adult birds were captured at night when they came to feed the chick. The chick-rearing period was divided into two sub-phases according to the chick age when the first long trip was performed by a parent as follows: early chick-rearing (from hatching until 20-day-old chicks; R1) and late chick-rearing (from 21- to 40 day-old chicks, R2). Devices were attached to the back feathers using three stripes of marine waterproof Tesa ${ }^{\circledR}$ tape (Wilson and Wilson 1989). The complete procedures lasted a maximum of $10 \mathrm{~min}$ after which the birds were released into the nest. The nests were checked for returning birds every day after device attachment. The birds were recaptured at the nest for recovering the devices which were carefully removed from feathers together with the tape. No nest desertion was observed during the study. Birds were sexed by bill measurements (Lo Valvo 2001) and vocalizations.

\section{Identification of foraging trip length}

The accelerometer recorded acceleration in three axes, according to the bird orientation: $X$ (head-tail), $Y$ (right-left), and $Z$ (dorso-ventral). Vectorial dynamic body acceleration was calculated $\left(\operatorname{VeDBA}(\mathrm{g})=\sqrt{a_{x}^{2}+a_{y}^{2}+a_{z}^{2}}\right)$ with 1 s smoothing, where $a_{x}, a_{y}$, and $a_{z}$ represent dynamic acceleration values from $X, Y$, and $Z$ axes, respectively (see also Gleiss et al. 2011). The acceleration data were used to identify birds' colony attendance by the "Resting at the colony" behaviour (Fig. 1) which was assigned when VeDBA was $\leq 0.1$. The duration of each foraging trip was calculated based on the end and the subsequent beginning of the "resting at the colony" behaviour. Only the first trip of each bird was included in analyses.

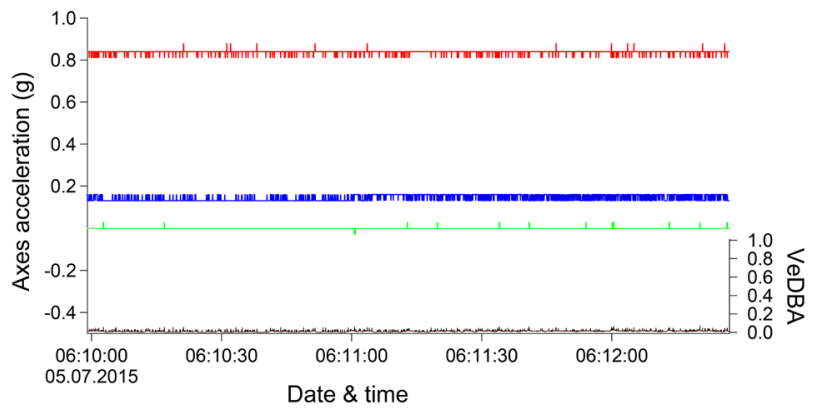

Fig. 1 Acceleration pattern of "Resting at the colony" behaviour: vectorial dynamic body acceleration $(\mathrm{VeDBA}) \leq 0.1 \mathrm{~g}$ (see details in "Methods"). VeDBA (black), $X$ (head-tail, green), $Y$ (right-left, blue), $Z$ (dorso-ventral, red)

Table 1 Mean $( \pm \mathrm{SD})$ trip length and dive parameters of Scopoli's shearwaters identified with accelerometer in all reproductive phases and sexes

\begin{tabular}{|c|c|c|c|c|c|c|}
\hline \multirow[b]{2}{*}{$\operatorname{Sex}(n)$} & \multicolumn{2}{|l|}{ Incubation } & \multicolumn{2}{|c|}{ Early chick-rearing } & \multicolumn{2}{|c|}{ Late chick-rearing } \\
\hline & Males $(n=12)$ & Females $(n=8)$ & Males $(n=12)$ & Females $(n=12)$ & Males $(n=8)$ & Females $(n=9)$ \\
\hline Mean trip length (days) & $6.9 \pm 2.5$ & $8.6 \pm 1.0$ & $1.2 \pm 0.6$ & $1.6 \pm 0.9$ & $3.2 \pm 2.3$ & $2.7 \pm 1.4$ \\
\hline Dive rates (dives day ${ }^{-1}$ ) & $34.8 \pm 24.5$ & $20.1 \pm 17.0$ & $48.7 \pm 41.2$ & $72.7 \pm 45.5$ & $17.6 \pm 9.7$ & $19.2 \pm 19.0$ \\
\hline Short dives $(<2 \mathrm{~s})$ & $19.3 \pm 12.4$ & $11.6 \pm 11.2$ & $23.0 \pm 16.7$ & $36.7 \pm 25.8$ & $9.5 \pm 6.0$ & $12.0 \pm 13.4$ \\
\hline Dive events $(\geq 2 \mathrm{~s})$ & $15.5 \pm 13.1$ & $8.5 \pm 7.0$ & $25.6 \pm 25.7$ & $36 \pm 21.7$ & $8.1 \pm 5.1$ & $7.2 \pm 6.4$ \\
\hline Mean duration of all dives (s) & $2.6 \pm 0.4$ & $2.5 \pm 0.6$ & $3.1 \pm 1.6$ & $2.7 \pm 0.6$ & $2.7 \pm 0.8$ & $2.1 \pm 0.6$ \\
\hline Mean duration of dive events (s) & $4.4 \pm 0.7$ & $4.1 \pm 0.8$ & $5.0 \pm 1.8$ & $4.3 \pm 0.9$ & $4.6 \pm 1.6$ & $4.1 \pm 1.3$ \\
\hline
\end{tabular}

The dive rates $\left(\right.$ dives day $^{-1}$ ) identified by accelerometers were divided into two groups according to the dive duration: short dives $(<2 \mathrm{~s})$ and dive events $(\geq 2 s)$ 


\section{Identification of dives}

Time-depth recorder (TDR) data were used to identify dives based on the pressure sensor. Atmospheric pressure $\left(P_{\mathrm{a}}\right.$ in $\left.\mathrm{mBar}, \approx 1025 \mathrm{mBar}\right)$ was estimated as a baseline of measured pressure $\left(P_{\mathrm{m}}\right.$ in $\left.\mathrm{mBar}\right)$. Then, the difference was converted in depth ( $D$ in $\mathrm{m}$ ) using the relationship: $D=0.01 \times\left(P_{\mathrm{m}}-P_{\mathrm{a}}\right)$, where $1 \mathrm{mBar}$ pressure difference corresponds to $0.01 \mathrm{~m}$ depth difference. Because the pressure sensor is very sensitive ( $5 \mathrm{mBar}$ ), considering very lowpressure variance as a dive might be misleading. Indeed, low-pressure differences might be caused by other behaviours (e.g., take off, fast turning). For this reason, only dives $\geq 0.2 \mathrm{~m}$ were considered. TDRs recorded dives with minimum duration $\geq 2 \mathrm{~s}$.

Dives recorded by TDRs were used to develop two algorithms for dive identification (see Supplementary Materials) using only accelerometer data and running on Igor Pro (WaveMetrics, Version 6.05). Specifically, we analysed data from four birds equipped with Axy-depth data loggers (TDR and accelerometer). First, we visually analysed the acceleration patterns ( $X, Y$, and $Z$ accelerations) corresponding to the dives detected by TDRs. This preliminary step aimed to identify characteristic acceleration patterns of dives. As we expected, $X$ acceleration (head-tail) effectively identified the bird orientation. Thus, only $X$ acceleration was used in the algorithm (see Fig. 2). Second, we set the threshold values of $X$ acceleration in each step of dive identification (see in the following) until a high overlap between the dives identified by the algorithm and the dives recorded by TDRs was reached. The first algorithm used the raw value of $\mathrm{X}$ acceleration. The starting point of a dive was defined by specific conditions: since dives had the shape of convex waves, $\mathrm{U}$ or $\mathrm{V}$-shape, the script filtered them if the value of $X$ acceleration reached $<-1$, representing a downward orientation of the bird (see Fig. 2a, step 1). Then, starting from there, the script scanned backwards in the descending part of the $\mathrm{X}$ wave until reaching $X=-0.3$, as this value defined the dive starting point (see Fig. 2a, step 2). The slopes of the smoothed $X$ acceleration-using boxcar algorithm with box size $3(0.12 \mathrm{~s})$ - were a condition to dive validation: it had to be smaller than -1 for at least $0.2 \mathrm{~s}$ from the starting point (i.e., a downward orientation lasting at least $0.2 \mathrm{~s}$ ). Then, the script scanned forward and determined the end of dive when $X>0$ and subsequently returned to 0 . This last part represented the ascending phase (see Fig. 2a, step 3). The second algorithm used a smoothed $X$ acceleration using a boxcar algorithm with box size 25 (1 s). First, the script found the smoothed $X<-0.5$, then scanned backward to find smoothed $X>-0.3$ as a starting point. Then, the script scanned forward and determined the end of dive when smoothed $X>0.5$. For each dive, the date/time and duration were calculated. We (a)

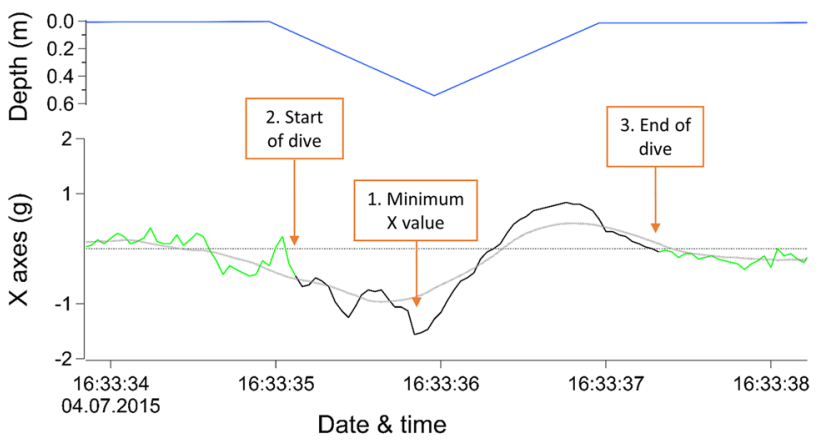

(b)

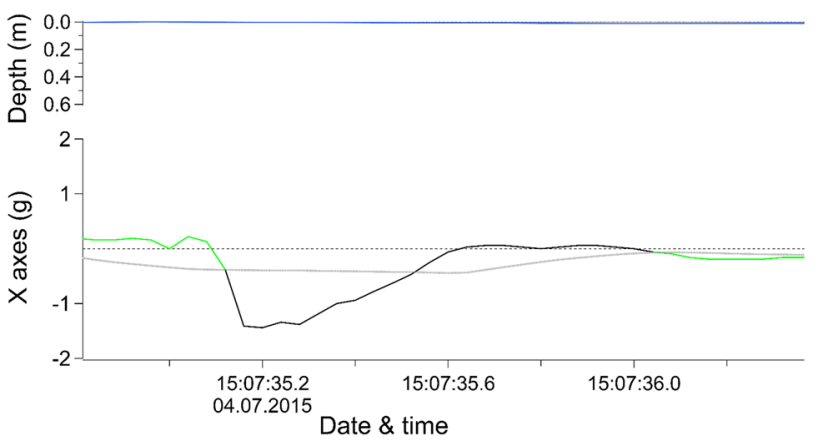

Fig. 2 Comparison between dives identified by the time-depth recorder (TDR) and the algorithm applied to accelerometer data. a Dive event: identified by TDR and algorithm (dive duration $\geq 2 \mathrm{~s}$ ). The three main steps for dive identification are indicated by arrows (see "Methods"). b Surface dive: very short duration dive (dive duration $<2 \mathrm{~s}$ ). Green absolute $X$ acceleration; grey static $X$ acceleration; black part identified as a dive by the algorithm

used both algorithms together to identify dives; hence, we refer to these only as "algorithm" hereafter. Dive data obtained by TDRs were only used to develop the algorithm and to test its reliability and were not included in statistical analyses.

\section{Data analysis}

The "Dive rate per day" (mean dives day ${ }^{-1}$ ) was calculated for each individual. The "Dive rate per hour" (dives $\mathrm{h}^{-1}$ ) was used only to compare night dive rates. Given that 1-day foraging trips did not include the whole night, we did not include trips with length $<2$ days to calculate dive rates per hour at night. We tested for differences between the proportion of males and females that performed at least one dive during night time using a Chi-squared test.

The effect of the reproductive phase (factorial variable with three levels) on "dive rate per day" was tested using Kruskal-Wallis rank sum test and post-hoc Dunn's test of multiple comparisons in the DescTools $\mathrm{R}$ package (Signorell 2015). The difference in the "Dive rate per day" between short and long foraging trips was tested with a 
Wilcoxon signed-ranks test. General linear model (GLM) was used to test the effect of "phase of reproduction" and "sex" as covariates on the "night dive rate per hour" as dependent variable. Distribution and spatial autocorrelation of residuals were checked using partial residual and quantile-quantile $\left(\mathrm{Q}^{\prime} \mathrm{Q}\right)$ plots. All statistical analyses were performed with $\mathrm{R}$ version 3.3.1 (R Core Team 2015).

\section{Results}

\section{Comparison of dive detection from TDR and accelerometer data}

Our algorithm based on acceleration data identified $87 \%$ of dives detected by TDR $(n=156)$, validating our method (for dives with depth $>0.5 \mathrm{~m}$, the correspondence between dives detected by algorithm and TDR increased to 94\%). These represented $17.7 \%$ of the total dives calculated by the algorithm using accelerometer data $(n=883$; Table 2$)$. Therefore, the algorithm detected almost five times more dives than the TDR $(n=727)$ : About $62.7 \%$ of dives identified only by the algorithm $(n=456)$ could not be detected by the TDR, because they were below the $1 \mathrm{~s}$ resolution of the device (Fig. 3a). The remaining 37.3\% $(n=271)$ were likely very shallow, i.e., below the $0.2 \mathrm{~m}$ depth. Indeed, most dives of Scopoli's shearwaters were very shallow, as around $50 \%$ of the dives identified by TDRs occurred in the first $0.5 \mathrm{~m}$ of depth and $78 \%$ were less than $1 \mathrm{~m}$ deep (Fig. 3b). The distribution of dive duration was comparable between the two devices (Fig. 3a).

\section{Trip length and dive analysis}

Given that the frequencies of trip length during chick-rearing had a bimodal distribution with a cut-off point at day 3 (Fig. 4), we divided all trips into short trips (trip length $\leq 3$ days) and long trips (trip length $>3$ days). Only long trips were observed during incubation and the maximum trip length was 10 days. During the entire duration of chickrearing, 1-day trips were the most frequent. Specifically, during the first 20 days after hatching (R1), the parents performed only short trips. Conversely, in R2, the birds performed both long and short trips resulting in a higher mean trip length (Table 1). The mean trip length was lowest during R1, followed by R2 and then INC (Kruskal-Wallis test, $H=43.2, P<0.001$; Dunn's test, R1-INC: mean rank diff $=-34, P<0.001 ;$ R2-INC: mean rank diff $=-22$, $P<0.001 ; \mathrm{R} 1-\mathrm{R} 2$ : mean rank diff $=-12, P=0.025)$. The average trips' length did not differ between the sexes (Wilcoxon sum of ranks test, $W=431.5, P>0.05$ ).

We identified a total of 7318 dives from accelerometer loggers: 4002 short dives (dive duration $<2$ s) and 3316
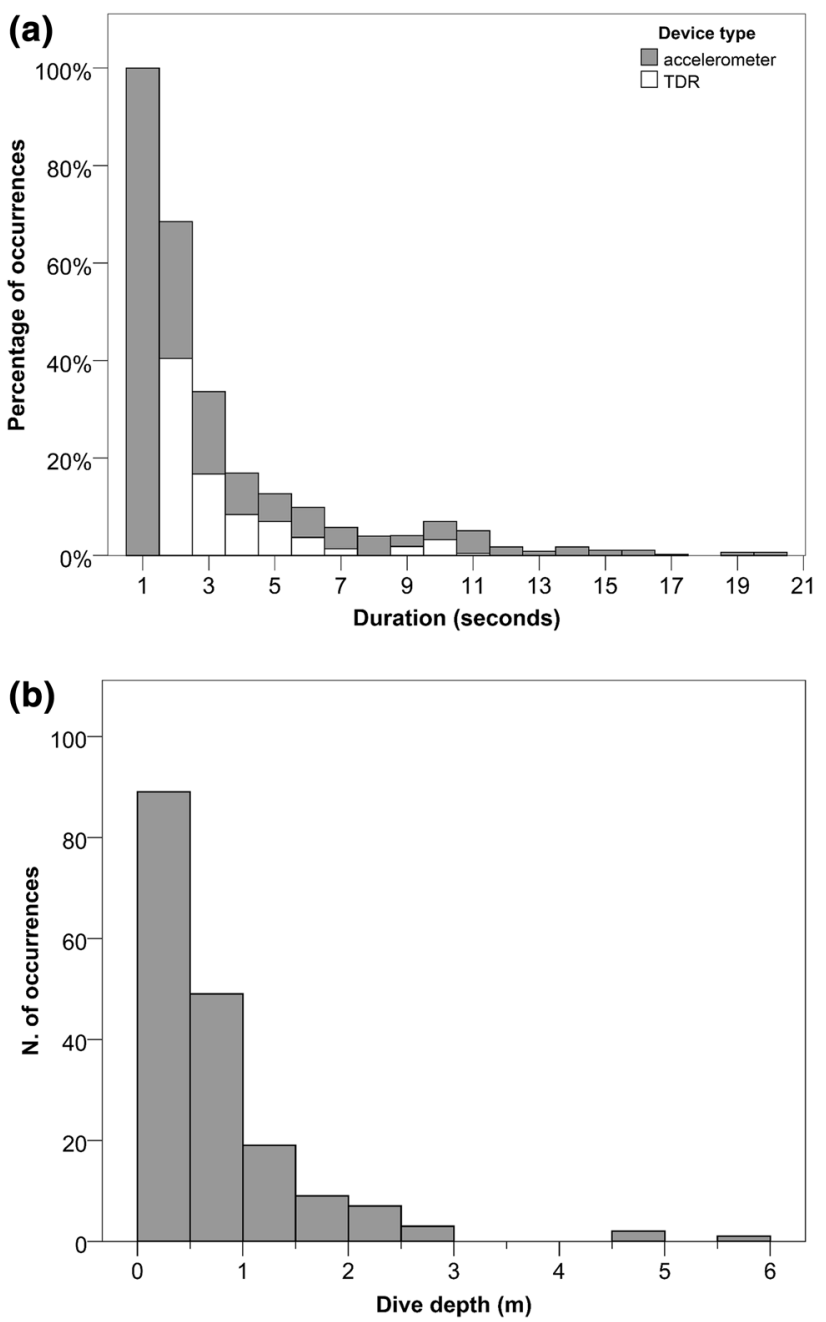

Fig. 3 a Percentage of occurrence of the duration of dives identified by time-depth recorders (TDR) and the algorithm applied to accelerometer data. b Dive depth distribution identified with TDR loggers in Scopoli's shearwaters

dive events (dive duration $\geq 2 \mathrm{~s}$ ). These groups were made according to the TDR minimum resolution of dive identification: short dives were not detectable from TDRs, being below the minimum resolution of the device $(2 \mathrm{~s})$. Given the very short duration of short dives, we assumed that they occurred close to the sea surface.

Since we did not find difference between short dives and dive events between phases and type of trip, we analysed all dives together. Birds performed on average $\pm \mathrm{SD}=202.4 \pm 145.9$ dives $(n=19)$ per trip during incubation and 84.7 \pm 156.4 dives $(n=41)$ during chick-rearing $(\mathrm{R} 1+\mathrm{R} 2)$. The mean dive rate per hour was $1.1 \pm 0.7(n=19)$ during incubation and $1.7 \pm 1.6(n=41)$ dives during chick-rearing $(\mathrm{R} 1+\mathrm{R} 2)$.

Dive rates per day differed among reproductive phases (Kruskal-Wallis test, $H=17.1, P<0.001$; Table 1). Specifically, Scopoli's shearwaters dived more often during 
Table 2 Mean $( \pm \mathrm{SD})$ values of dive parameters from four birds equipped with timedepth recorders (TDRs) and accelerometers

\begin{tabular}{lllll}
\hline & Dives from TDR & $\begin{array}{l}\text { All dives from } \\
\text { acc. }\end{array}$ & $\begin{array}{l}\text { Dive events from } \\
\text { acc. }(\geq 2 \mathrm{~s})\end{array}$ & $\begin{array}{l}\text { Short dives } \\
\text { from acc. } \\
(<2 \mathrm{~s})\end{array}$ \\
\hline$N$ dives total & 179 & 883 & 427 & 456 \\
Mean dive depth & $0.78 \pm 0.79$ & $\mathrm{ND}$ & $\mathrm{ND}$ & $\mathrm{ND}$ \\
Dive mean duration (s) & $3.4 \pm 2.1$ & $3.2 \pm 4$ & $5.7 \pm 4.7$ & 1 \\
\hline
\end{tabular}

Dives identified by accelerometers were divided into two groups according to the dive duration calculated by the algorithm from acceleration data: short dives $(<2 s)$ and dive events $(\geq 2 \mathrm{~s})$. Short dives were not detectable by TDRs due to the short duration. Standard deviations were reported with means (mean \pm SD)

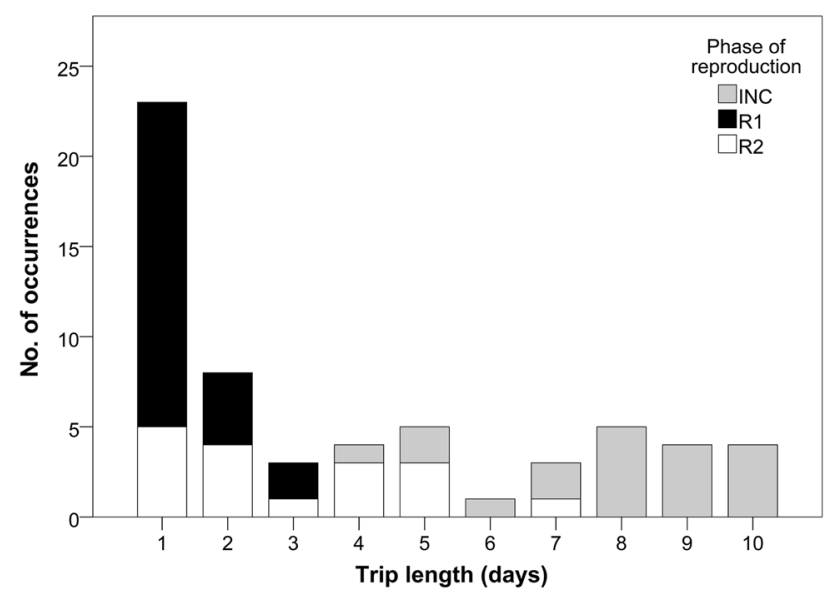

Fig. 4 Distribution of foraging trip length during (INC) incubation (black), (R1) early chick-rearing (white), and (R2) late chick-rearing (grey). Trips were classified according to the bimodal distribution of trip frequencies during chick rearing, dividing short ( $\leq 3$ days) from long ( $\geq 4$ days) trips

R1 compared with INC (Dunn's test, R1-INC: mean rank diff $=14.5, P=0.01$ ) and R2 (Dunn's test, R1-R2: mean rank diff $=22.1, P<0.001$ ). Birds dived more frequently during short trips compared with long trips (Wilcoxon signed-ranks test, $W=591, N=60, P=0.03$ ).

On average, birds of both sexes dived less frequently at night, during all phases (Wilcoxon sum of ranks test, $W=1289, P<0.001)$. Considering only the night dives, birds dived more frequently during early chick-rearing, compared with other reproductive phases (Table 3). Males performed more night dives than females (Table 3, see Supplementary Materials). Furthermore, a higher number of males performed at least one dive at night compared to females (Chi-square test, $X=6.4, P=0.01$ ).

The dive rate was higher in the early morning and early afternoon (Fig. 5a). Females performed more dives than males in the afternoon (Fig. 5b). During early chickrearing, birds dived more intensively in the early morning and in the late afternoon compared with other phases (Fig. 5c).
Table 3 Results from the general linear model (Identity link function) of the effect of (1) "sex" and (2) "phase" (incubation:INC, early chick-rearing:R1, and late chick-rearing:R2) on the "night dive rate $\left(\right.$ dives $\mathrm{h}^{-1}$ )", followed by Tukey post-hoc test

\begin{tabular}{llll}
\hline & Estimate (SE) & $F_{2,54}$ & $P$ \\
\hline Night dive rate $\left(\right.$ dives $\left.^{-1}\right)$ & & \\
Intercept & $2.08(2.19)$ & & 0.347 \\
Sex & & 4.23 & $0.046^{*}$ \\
$\quad$ Males-Females & $4.98(2.34)$ & & \\
Phase & & 5.62 & $0.007^{*}$ \\
R1-INC & $7.17(3.04)$ & & 0.059 \\
R1-R2 & $10.9(3.3)$ & & $0.005^{*}$ \\
INC-R2 & $3.7(2.7)$ & & 0.36 \\
\hline
\end{tabular}

*Significant results $(P<0.05)$

\section{Discussion}

We developed an algorithm to identify dive events using only accelerometer data. To our knowledge, this is the first study where diving activities, including very shallow dives, were identified in a shallow-diving seabird. We measured dive rates and foraging trip lengths to describe parental foraging effort during three reproductive phases (incubation, early chick-rearing, and late chick-rearing). Our results suggest that Scopoli's shearwaters vary their foraging effort according to the phase of reproduction. The maximum effort was observed during the early chick-rearing phase when parents performed only short trips with the highest dive rate. Moreover, birds dived more frequently during short than during long trips. Finally, although foraging effort was similar between sexes, males performed more dives than females during the night.

\section{Identification of dives}

Using time-depth recorders (TDRs), we detected only $17.7 \%$ of the dives identified by the algorithm. Most of the dives detected by the algorithm $(82.3 \%)$ were not identified by the TDRs, being either too short in duration $(<2 \mathrm{~s})$ or because they probably occurred in very shallow water. We assumed that short duration dives, which accounted for 

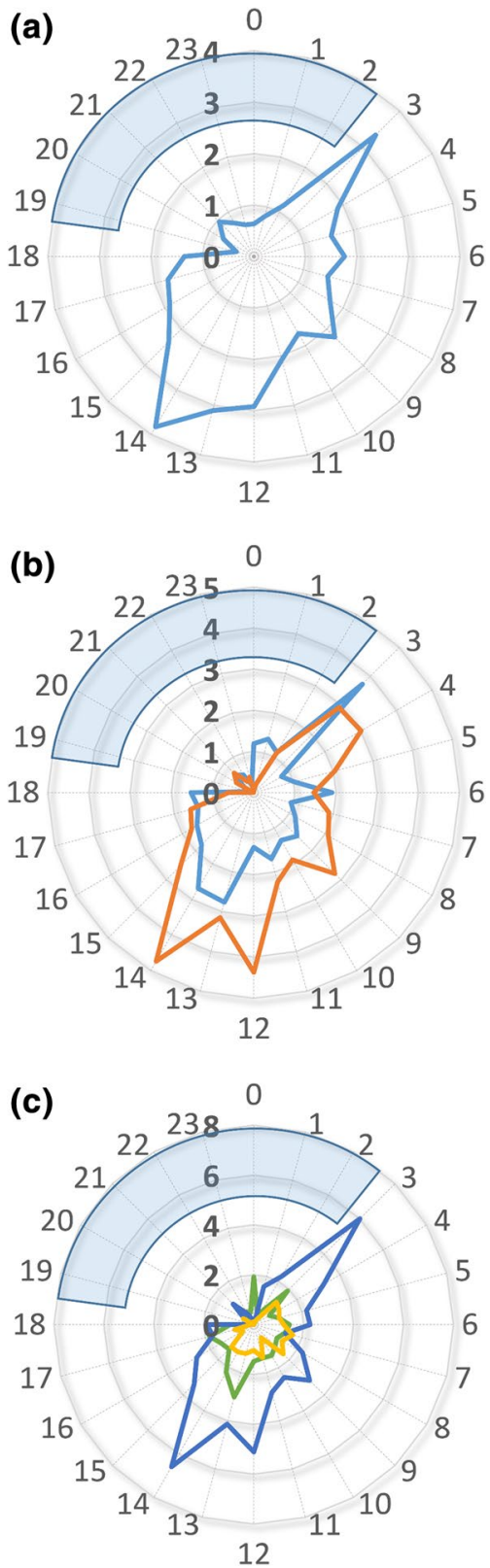

Fig. 5 Radar plot of dive rates (dives $\mathrm{h}^{-1}$ ) for a all dives, $\mathbf{b}$ males (blue) and females (red), $\mathbf{c}$ incubation (green), early chick-rearing (blue) and late chick-rearing (yellow). Time in GMT 0 (local time area GMT +2). Night time between 18:30 and 2:30 (GMT 0)

$55 \%$ of all dives performed by birds, were shallow or even from the sea surface. The prevalence of shallow dives in Scopoli's shearwaters was also confirmed by the depth data recorded by TDRs: $50 \%$ of dives were registered in the first $0.5 \mathrm{~m}$ of depth and $78 \%$ were less than $1 \mathrm{~m}$ deep. Similarly, in many seabird species, dives are predominantly less than $5 \mathrm{~m}$ deep (Paiva et al. 2010a; Rollinson et al. 2014; Meier et al. 2015). In these species, the number of shallow dives recorded with TDR was most likely underestimated. Therefore, our algorithm can increase the knowledge of the foraging ecology of other shallow divers. This is an important result, because until now, the identification of shallow dives has always been limited by the pressure and time resolution of TDRs in shallow-diving seabirds (Grémillet et al. 2014).

Although it is known that Scopoli's shearwaters feed often very close to the sea surface (Zotier et al. 1999), to our knowledge, such a high proportion of shallow and short duration dives ( $82.3 \%$ of total) has never been recorded in a seabird species before. Since seabirds feed mostly on the sea surface when exploiting fishery discards (Grémillet et al. 2008), the high number of shallow dives recorded in Scopoli's shearwater might reflect extensive use of fisheries discards by the birds in this study.

A better knowledge of the foraging ecology of threatened shallow-diving seabirds can be crucial when planning future conservation actions. In the Mediterranean Sea, commercial fisheries produce huge amounts of discards and offal which are made available for marine species (Kelleher 2005). Some threatened species, such as the Balearic shearwater (Puffinus mauretanicus), largely exploit fisheries' discards (Arcos and Oro 2002). A large amount of surface dives in particular conditions might indicate that birds feed predominantly on fisheries discards. Studies using accelerometers may thus help to assess and quantify the use of discards in several seabirds.

It is apparent that TDRs alone can detect only a little part of the dives in a shallow diving seabird and that TDRs, therefore, cannot provide reliable data about the foraging ecology in such species. TDR needs to be in contact with water for a certain time and in a certain depth to successfully record a dive. Conversely, accelerometers, using only body acceleration, can identify even very shallow dives, where birds might only partially immerse their body into the water, in a very typical way for many Procellariiformes (Ashmole 1971). Dive data from previous studies on Scopoli's shearwater are in line with our results: Grémillet et al. (2014) recorded $9 \pm 8$ (2012) and 49 \pm 47 (2013) dives per trip using TDRs during chick-rearing, while our algorithm recorded $84.7 \pm 156.4$ dives per trip in the same period. Rubolini et al. (2015) recorded an average of $0.35 \pm 0.02$ dives per hour using compass loggers during chick-rearing. Compass loggers identified dives using temperature variations recording every $5 \mathrm{~s}$. In the same reproductive phase, our algorithm identified $1.7 \pm 1.6$ dives per hour. Time interval of $5 \mathrm{~s}$ of compass logger was not sufficient to record short dives, since $85.8 \%$ of dives recorded by the algorithm were shorter than $5 \mathrm{~s}$.

Our algorithm identified $87 \%$ of the dives deeper than $0.2 \mathrm{~m}$ obtained by the TDR and $94 \%$ of dives deeper than $0.5 \mathrm{~m}$. The high overlap between dives identified by TDR and algorithm validated our method. However, the dive accuracy of identifications of the algorithm decreased with 
shallower dive depths. Short dives were more difficult to detect by the algorithm, probably due to less defined shape of short dives. Although our algorithm was able to identify a relatively high number of shallow dives, this might still underestimate the number of surface dives.

Since it was not possible to video-record the diving behaviours of birds, we could not exclude the possibility that our algorithm and the TDR detected some preening event. However, we visually observed that many preening events happened with a rhythmic upward or right-left bird orientation which would not be classified as a dive by the algorithm.

\section{Effect of phase and trip type on foraging effort}

During incubation, parents performed only long foraging trips for self-provisioning, as observed in a previous study in the same colony (Cecere et al. 2013). In this phase, birds forage for themselves and they can exploit highly productive areas far away from the colony (Paiva et al. 2010a). Later, parents reduced their mean trip length during chick-rearing phase. During this period, the energetic demands of the parents increase (Shaffer et al. 2003; Navarro et al. 2007), since they must feed both their chick and themselves. Our observations showed that Scopoli's shearwater foraging ecology changed also within the chickrearing period. Specifically, the highest foraging effort was observed at the early chick-rearing. In this phase, adults performed only short trips and dived more frequently compared to the late chick-rearing period.

The change of foraging strategy can be explained considering both parental duties and environmental constraints during short and long foraging trips. During short trips, Scopoli's shearwaters from Linosa have only access to low productive foraging areas surrounding the colony (Cecere et al. 2014) due to the need to feed the chick frequently. Therefore, parents increased their foraging effort at the beginning of chick-rearing to maximise the energy delivery to the chick in time constraint conditions, in accordance with the model proposed by Ydenberg et al. (1994). However, short foraging trips are very expensive for parents, which lose weight, as observed in some albatross species (Weimerskirch et al. 1994; Stahl and Sagar 2000; Terauds and Gales 2006). In line with this, birds dived more frequently in short trips compared with long trips. The high number of dives recorded in this study during short trips is in accordance with Paiva et al. (2010b) who recorded an increase of birds diving effort in Cory's shearwater (Calonectris borealis) when foraging over low productivity waters.

The high foraging effort performed by birds in the early chick-rearing is also supported by night-time foraging activity: we found an increase of diving activity at night during early chick-rearing compared with other phases. Although nocturnal foraging might be less profitable than diurnal foraging (McNeil et al. 1993), parents might need to continue foraging during night during highly energetically demanding periods.

During the late chick-rearing period, parents performed both long and short trips. Birds need to perform long trips to replenish their energy reserves after short trips (Baduini and Hyrenbach 2003) having access to more profitable foraging areas (Paiva et al. 2010a). As a consequence, we observed a lower foraging effort during late chick-rearing compared with the early phase of chick-rearing, as birds dived less frequently.

Surprisingly, we did not find differences in dive frequency between incubation and late chick-rearing, even though several studies suggested an increase of parents foraging effort during chick-rearing (Shaffer et al. 2003; Navarro et al. 2007). Nevertheless, these studies considered chick-rearing as a single phase covering possible differences in birds' foraging activity over it.

\section{Effect of daytime and sex on foraging effort}

Dive frequency in Scopoli's shearwater was not constant over the day. We found two peaks in the dive rate: at dawn and between 12:00 and 14:00 GMT (14:00-16:00 local time). A peak in diving activity at dawn was also observed in Sooty shearwaters (Puffinus griseus) (Shaffer et al. 2009), and this might allow birds to take advantage of the vertical migration of certain prey species (e.g., squid) which ascend during night. The second peak might be due to the birds' arrival to potential foraging areas (Grémillet et al. 2004). The peak of dives during afternoon was more prominent during early chick-rearing. Given that birds performed only short trips during early chick-rearing, the number of dives during the afternoon was higher during short trips than during long trips. The dive rates per hour recorded in this study differed from observations of Rubolini et al. (2015) who noticed a peak of dive activity at 21:00 (local time) when we observed the minimum dive rates. This difference might be methodological, based on the estimation of dive occurrences using compass loggers. Given that compass loggers use only temperature variation to record a dive, is it possible that some of their recordings might be preening events instead of real dives. Indeed, at 21:00, birds usually aggregate in front of the colony (raft) waiting for good conditions to visit the nest (Rubolini et al. 2015).

Mean trip lengths and dive rates were similar between males and females. Our results are in accordance with those of other studies which investigated sex difference in foraging activity (Phalan et al. 2007; Zavalaga et al. 2010) and trip length (Ramos et al. 2009). Nevertheless, 
males dived more frequently than females during nighttime. Moreover, almost all males (17/18) performed at least one dive during night-time compared to 13 of 20 females. We observed a peak in the number of dives during the afternoon performed by females. Conversely, males showed a more constant dive activity during the day. The sexual dimorphism in this species might explain the difference of foraging behaviour between sexes: Scopoli's shearwater males are larger than females in body mass, wing surface (Massa and Lo Valvo 1986), and wing loading. Since some birds might prolong their foraging trip overnight, because they did not forage enough during day-time (Bolton 1996), males could need to feed more frequently at night than females due to their size and higher flight cost, which is positively correlated with wing loading (Hertel and Ballance 1999). However, the different dive patterns of males and females might also be caused by a different feeding strategy. Some prey species, such as squid, migrate to the surface during night. Males might exploit these species at the sea surface more frequently than females to reduce flying time (Navarro et al. 2007). Thus, although our study enhanced the knowledge of sex differences in foraging behaviours, further investigations would be necessary in the future.

\section{Conclusion}

In this study, we developed a new method to accurately estimate foraging activity in a shallow-diving seabird using only accelerometer data. In Scopoli's shearwater, most of dives were very short and occurred close to the sea surface. This was an important result since TDR (time-depth recorder) underestimated the foraging behaviour in this species and likely in other shallow-diving seabirds. Our algorithm can enhance the knowledge of the foraging ecology of several shallow diving birds, where the TDRs do not reliably detect shallow dives. The high accuracy and small size of accelerometers can effectively allow detailed studies on shallow-diving species and medium-sized seabirds that cannot be equipped with other loggers due to size or weight limitation. Our algorithm can be used concurrently with TDR to provide reliable data about the foraging ecology of several seabirds. The algorithm can effectively identify shallow dives from accelerometer data, while TDR data provides depth information for deeper dives.

Acknowledgements We wish to thank all people who participated in the fieldwork: Lucie Michel, Paolo Becciu, Enrica Martorelli, Katrin Quiring, Wiebke Schaefer, and Giulia Bambini. Thanks to Giacomo Dell'Omo for field work logistic. The project was supported by Ornis italica, Deutsche Forschungsgemeinschaft (PQ 148/8 and PQ 148/17), and the LIFE11 + NAT/IT/000093 'Pelagic Birds'.

\section{Compliance with ethical standards}

Conflict of interest The authors declare that they have no conflict of interest.

Consent was obtained from all participants of the study. All animals were sampled and/or treated according to the national legislation. The study was conducted under a permit issued by the Regione Siciliana and Assessorato Risorse Agricole e Alimentari.

\section{References}

Arcos JM, Oro D (2002) Significance of fisheries discards for a threatened Mediterranean seabird, the Balearic shearwater Puffinus mauretanicus. Mar Ecol Prog Ser 239:209-220. doi:10.3354/ meps 239209

Ashmole NP (1971) Seabird ecology and the marine environment. In: Farner DS, King JR (eds) Avian biology. Academic Press, New York, pp 223-286

Baduini CL, Hyrenbach KD (2003) Biogeography of procellariiform foraging strategies: does ocean productivity influence provisioning? Mar Ornithol 31:101-112

Berlincourt M, Angel LP, Arnould JPY (2015) Combined use of GPS and accelerometry reveals fine scale three-dimensional foraging behaviour in the short-tailed shearwater. PLoS One 10:1-16. doi:10.1371/journal.pone.0139351

Bolton M (1996) Energy expenditure, body weight and foraging performance of Storm Petrels Hydrobates pelagicus breeding in artificial nesting chambers. Ibis 138(3):405-409

Cecere JG, Catoni C, Maggini I, Imperio S, Gaibani G (2013) Movement patterns and habitat use during incubation and chick-rearing of Cory's shearwaters (Calonectris diomedea diomedea) (Aves: Vertebrata) from Central Mediterranean: influence of seascape and breeding stage. Ital J Zool 80:82-89. doi:10.1080/112 50003.2012.710654

Cecere JG, Gaibani G, Imperio S (2014) Effects of environmental variability and offspring growth on the movement ecology of breeding scopoli's shearwater Calonectris diomedea. Curr Zool 60:622-630. doi:10.1093/czoolo/60.5.622

Chimienti M, Cornulier T, Owen E, Bolton M, Davies IM, Travis JM, Scott BE (2016) The use of an unsupervised learning approach for characterizing latent behaviors in accelerometer data. Ecol Evol 6(3):727-741. doi:10.1002/ece3.1914

Congdon BC, Krockenberger AK, Smithers BV (2005) Dual-foraging and coordinated provisioning in a tropical Procellariiform, the wedge-tailed shearwater. Mar Ecol Prog Ser 301:293-301. doi:10.3354/meps301293

Dias MP, Granadeiro JP, Catry P (2012) Working the day or the night shift? Foraging schedules of Cory's shearwaters vary according to marine habitat. Mar Ecol Prog Ser 467:245-252. doi:10.3354/ meps09966

Gleiss AC, Wilson RP, Shepard ELC (2011) Making overall dynamic body acceleration work: on the theory of acceleration as a proxy for energy expenditure. Methods Ecol Evol 2:23-33. doi:10.1111/j.2041210X.2010.00057.x

Gómez Laich A, Wilson RP, Gleiss AC, Shepard EL, Quintana F (2011) Use of overall dynamic body acceleration for estimating energy expenditure in cormorants. J Exp Mar Bio Ecol 399:151155. doi:10.1016/j.jembe.2011.01.008

Granadeiro J, Nunes M, Silva M, Furness R (1998) Flexible foraging strategy of Cory's shearwater, Calonectris diomedea, during the chick-rearing period. Anim Behav 56:1169-1176. doi:10.1006/ anbe.1998.0827 
Grémillet D, Dell'Omo G, Ryan PG, Peters G, Ropert-Coudert Y, Weeks SJ (2004) Offshore diplomacy, or how seabirds mitigate intra-specific competition: A case study based on GPS tracking of Cape gannets from neighbouring colonies. Mar Ecol Prog Ser 268:265-279. doi:10.3354/meps268265

Grémillet D, Pichegru L, Kuntz G, Woakes AG, Wilkinson S, Crawford RJM, Ryan PG (2008) A junk-food hypothesis for gannets feeding on fishery waste. Proc R Soc Lond Biol 275:1149-1156. doi:10.1098/rspb.2007.1763

Grémillet D, Péron C, Pons J-B, Ouni R, Authier M, Thévenet M, Fort J (2014) Irreplaceable area extends marine conservation hotspot off Tunisia: insights from GPS-tracking Scopoli's shearwaters from the largest seabird colony in the Mediterranean. Mar Biol 161:2669-2680. doi:10.1007/s00227-0142538-z

Guilford TC, Meade J, Freeman R, Biro D, Evans T, Bonadonna F, Boyle D, Roberts S, Perrins CM (2008) GPS tracking of the foraging movements of Manx shearwaters Puffinus puffinus breeding on Skomer Island, Wales. Ibis 150:462-473. doi:10.1111/j.1474-919x.2008.00805.x

Hertel F, Ballance L (1999) Wing ecomorphology of seabirds from Johnston Atoll. Condor 101:549-556

Jonsen ID, Flemmings JM, Myers RA (2005) Robust state-space modeling of animal movement data. Ecology 86:2874-2880. doi:10.1890/04-1852

Kelleher K (2005) Discards in the world's marine fisheries: an update. FAO Fish Tech Pap 470:131

Lo Valvo M (2001) Sexing dult Cory's shearwater by discriminant analysis of body measurements on Linosa Island (Sicilian Channel), Italy. Waterbirds 24:169-174.

Magalhães M, Santos R, Hamer K (2008) Dual-foraging of Cory's shearwaters in the Azores: feeding locations, behaviour at sea and implications for food provisioning of chicks. Mar Ecol Prog Ser 359:283-293. doi:10.3354/meps07340

Massa B, Lo Valvo M (1986) Biometrical and biological considerations on the Cory's shearwater Calonectris diomedea. In: Mediterranean Marine Avifauna. Springer, Berlin, pp 293-313

McNeil R, Drapeau P, Pierotti R (1993) Nocturnality in colonial waterbirds: occurrence, special adaptations, and suspected benefits. In: Power DM (ed) Current ornithology, vol 10. Plenum Press, New York, pp 187-246

Meier RE, Wynn RB, Votier SC, Grive MM, Rodriguez A, Maurice L, Van Loon EE, Jones AR, Suberg L, Arcos JM, Morgan G, Josey SA, Guilford T (2015) Consistent foraging areas and commuting corridors of the critically endangered Balearic shearwater Puffinus mauretanicus in the northwestern Mediterranean. Biol Conserv 190:87-97

Navarro J, González-solís J, Viscor G (2007) Nutritional and feeding ecology in Cory's shearwater Calonectris diomedea during breeding. Mar Ecol Prog Ser 351:261-271. doi:10.3354/ meps07115

Navarro J, Kaliontzopoulou A, Gonzàlez-Solìs J (2009) Sexual dimorphism in bill morphology andfeeding ecology in Cory's shearwater (Calonectris diomedea). Zoology 112:128-138. doi:10.1016/j.zool.2008.05.001

Ochi D, Oka N, Watanuki Y (2010) Foraging trip decisions by the streaked shearwater Calonectris leucomelas depend on both parental and chick state. J Ethol 313-321. doi:10.1007/ s10164-009-01873

Paiva VH, Geraldes P, Ramírez I, Meirinho A, Garthe S, Ramos JA (2010a) Foraging plasticity in a pelagic seabird species along a marine productivity gradient. Mar Ecol Prog Ser 398:259-274. doi: $10.3354 /$ meps08319

Paiva VH, Geraldes P, Ramírez I, Meirinho A, Garthe S, Ramos JA (2010b) Oceanographic characteristics of areas used by Cory's shearwaters during short and long foraging trips in the North Atlantic. Mar Biol 157:1385-1399. doi:10.1007/ s00227-010-1417-5

Phalan B, Phillips RA, Silk JRD et al (2007) Foraging behaviour of four albatross species by night and day. Mar Ecol Prog Ser 340:271-286. doi:10.3354/meps340271

Pinaud D, Weimerskirch H (2005) Scale-dependent habitat use in a long-ranging central place predator. J Anim Ecol 74:852-863. doi:10.1111/j.1365-2656.2005.00984.x

Quillfeldt P, Masello JF, Hamer KC (2004) Sex differences in provisioning rules and honest signalling of need in Manx shearwaters, Puffinus puffinus. Anim Behav 68:613-620. doi:10.1016/j. anbehav.2003.12.002

R Core Team (2015) R: a language and environment for statistical computing. Version 3.2.1. R Foundation for Statistical Computing, Vienna. https://www.R-project.org/

Ramos JA, Moniz Z, Solá E, Monteiro LR (2003) Reproductive measures and chick provisioning of Cory's shearwater Calonectris diomedea borealis in the Azores. Bird Study 50:47-54. doi:10.1080/00063650309461289

Ramos JA, Granadeiro JP, Phillips RA, Catry P (2009) Flight morphology and foraging behavior of male and female Cory's shearwaters. Condor 111:424-432. doi:10.1525/cond.2009.090008

Rollinson DP, Dilley BJ, Ryan PG (2014) Diving behaviour of whitechinned petrels and its relevance for mitigating longline bycatch. Polar Biol 37(9):1301-1308. doi:10.1007/s00300-014-1521-y

Ronconi RA, Ryan PG, Ropert-Coudert Y (2010) Diving of great shearwaters (Puffinus gravis) in cold and warm water regions of the South Atlantic Ocean. PLoS One 5(11):e15508. doi:10.1371/ journal.pone.0015508

Ropert-Coudert Y, Kato A, Wilson RP, Cannell B (2006) Foraging strategies and prey encounter rate of free-ranging Little Penguins. Mar Biol 149:139-148. doi:10.1007/s00227-005-0188-x

Rubolini D, Maggini I, Ambrosini R et al (2015) The effect of moonlight on Scopoli's shearwater Calonectris diomedea colony attendance patterns and nocturnal foraging: a test of the foraging efficiency hypothesis. Ethology 121(3):284-299. doi:10.1111/ eth. 12338

Sakamoto KQ, Sato K, Ishizuka M, Watanuki Y, Takahashi A, Daunt F, Wanless S (2009) Can ethograms be automatically generated using body acceleration data from free-ranging birds? PLoS One 4:e5379. doi:10.1371/journal.pone.0005379

Sangster G, Collinson JM, Crochet PA, Knox AG, Parkin DT, Votier SC (2012) Taxonomic recommendations for British birds: eighth report. Ibis 154:874-883. doi:10.1111/j.1474-919X.2012.01273.x

Shaffer SA, Costa DP, Weimerskirch H (2003) Foraging effort in relation to the constraints of reproduction in free-ranging albatrosses. Funct Ecol 17:66-74. doi:10.1046/j.1365-2435.2003.00705.x

Shaffer A, Weimerskirch H, Scott D, et al. (2009) Spatio temporal habitat use by breeding Sooty shearwaters Puffinus griseus. Mar Ecol Prog Ser 391:209-220. doi:10.3354/meps07932

Shepard E, Wilson R, Halsey L, et al. (2008) Derivation of body motion via appropriate smoothing of acceleration data. Aquat Biol 4:235-241. doi:10.3354/ab00104

Signorell A (2015) DescTools: tools for descriptive statistics. R package version $0.99, \mathrm{p} 15$

Spear LB, Ainley DG, Walker WA (2007) Foraging dynamics of seabirds in the Eastern Tropical Pacific Ocean. Studies in Avian Biology Series 35: Cooper Ornithological Society, Norman

Stahl JC, Sagar PM (2000) Foraging strategies and migration of southern Buller's albatrosses Diomedea b. bulled breeding on the Solander Is, New Zealand. J R Soc New Zeal 30:319-334. doi:10 .1080/03014223.2000.9517625

Terauds A, Gales R (2006) Provisioning strategies and growth patterns of light-mantled sooty albatrosses Phoebetria palpebrata 
on Macquarie Island. Polar Biol 29:917-926. doi:10.1007/ s00300-006-0133-6

Tremblay Y, Roberts AJ, Costa DP (2007) Fractal landscape method: an alternative approach to measuring area-restricted searching behavior. J Exp Biol 210:935-945. doi:10.1242/jeb.02710

Weimerskirch H (1998) How can a pelagic seabird provision its chick when relying on a distant food resource? Cyclic attendance at the colony, foraging decision and body condition in sooty shearwaters. J Anim Ecol 67:99-109. doi:10.1046/j.1365-2656.1998.00180.x

Weimerskirch H, Chastel O, Ackermann L, Chaurand T, CuenotChaillet F, Hindermeyer X, Judas J (1994) Alternate long and short foraging trips in pelagic seabird parents. Anim Behav $472-476$
Wilson RP, Wilson M-PTJ (1989) Tape: a package attachment technique for penguins. Wildl Soc Bull 17:77-79.

Ydenberg R, Welham C, Schmid-Hempel R (1994) Time and energy constraints and the relationships between currencies in foraging theory. Behav Ecol 5(1):28-34

Zavalaga CB, Halls JN, Mori GP, Taylor SA, Dell'Omo G (2010) Atsea movement patterns and diving behavior of Peruvian boobies Sula variegata in northern Perù. Mar Ecol Prog Ser 404:259274. doi: $10.3354 /$ meps 08490

Zotier R, Bretagnolle V, Thibault J-C (1999) Biogeography of the marine birds of a confined sea, the Mediterranean. J Biogeogr 26:297-313 